\title{
Thermally-Induced Alterations of Bentonite Backfilled Repositories: THMC Modeling and Testing
}

JENS BIRKHOLZER, LIANGE ZHENG, JONNY RUTQVIST ${ }^{1}$

LBNL, Berkeley, CA, 94720, USA, jtbirkholzer@lbl.gov

This presentation gives on overview of the complex thermo-hydro-mechanical and chemical (THMC) processes occurring upon the disposal of heat-producing high-level radioactive waste in geologic repositories. A specific focus is on the role of compacted bentonite which is commonly used as an engineered backfill material for emplacement tunnels because of its low permeability, high swelling pressure, and radionuclide retention capacity. Laboratory and field tests integrated with THMC modeling have provided an effective way to deepen our understanding of temperature-related perturbations; however, most of this work has been conducted for maximum temperatures around $100^{\circ} \mathrm{C}$. In contrast, some international disposal programs have recently started investigations to understand whether local temperatures in the bentonite of up to $200^{\circ} \mathrm{C}$ could be tolerated with no significant changes to safety relevant properties. Raising the maximum temperature is attractive for economical and safety reasons, but faces the challenge of exposing the bentonite to significant temperatures increases. Strong thermal gradients may induce complex moisture transport processes while geochemical processes such as cementation and perhaps also illitization effects may occur, all of which could strongly affect the bentonite and near-field rock properties.

Here, we present initial investigations of repository behavior exposed to strongly elevated temperatures. We will start discussing our current knowledge base for tempature effects in repositories exposed to a maximum temperature of $100^{\circ} \mathrm{C}$, based on data and related modeling analysis from a large heater experiments conducted for over 18 years in the Grimsel Test Site in Switzerland. We then show results from coupled thermal, hydrological, mechanical and chemical (THMC) simulations of a nuclear waste repository in a clay formation exposed to a maximum temperature of $200^{\circ} \mathrm{C}$. We also explore preliminary data from a bench-scale laboratory mockup experiment which was designed to represents the strong THMC gradients occurring in a "hot" repository, and we finally touch on a full-scale field experiment to be conducted soon in the Grimsel Test Site underground research laboratory in Switzerland (referred to as HotBENT). 